\title{
Anti-Parasitic Activity of Cherry Tomato Peel Powders
}

\author{
Mendel Friedman ${ }^{1} *$, Christina C. Tam ${ }^{2}$, Jong H. Kim ${ }^{2}$ D , Sydney Escobar ${ }^{3}$, Steven Gong ${ }^{3} \mathbb{D}, \mathrm{Max}^{\mathrm{Liu}}{ }^{3}$, \\ Xuan Yu Mao ${ }^{3}$, Cindy Do ${ }^{3}$, Irene Kuang ${ }^{3}$, Kelvin Boateng ${ }^{3}$, Janica $\mathrm{Ha}^{3}{ }^{3}$, Megan Tran ${ }^{3}$, Srimanth Alluri ${ }^{3}$, \\ Tam Le $^{3}$, Ryan Leong ${ }^{3}$, Luisa W. Cheng ${ }^{2}$ and Kirkwood M. Land ${ }^{3}$
}

1 Healthy Processed Foods Research Unit, Agricultural Research Service, United States Department of Agriculture, Albany, CA 94710, USA

2 Foodborne Toxins Detection and Prevention Research Unit, Agricultural Research Service, United States Department of Agriculture, Albany, CA 94710, USA; christina.tam@usda.gov (C.C.T.); jongheon.kim@usda.gov (J.H.K.); luisa.cheng@usda.gov (L.W.C.)

3 Department of Biological Sciences, University of the Pacific, Stockton, CA 95211, USA; s_escobar1@u.pacific.edu (S.E.); s_gong3@u.pacific.edu (S.G.); m_liu11@u.pacific.edu (M.L.); s_mao@u.pacific.edu (X.Y.M.); c_do4@u.pacific.edu (C.D.); i_kuang@u.pacific.edu (I.K.); k_boateng@u.pacific.edu (K.B.); j_ha8@u.pacific.edu (J.H.); m_tran59@u.pacific.edu (M.T.); s_alluri@u.pacific.edu (S.A.); yentam7160@gmail.com (T.L.); r_leong2@u.pacific.edu (R.L.); kland@pacific.edu (K.M.L.)

* Correspondence: mendel.friedman@usda.gov or mendel587@aol.com; Tel.: +1-510-559-5615

check for updates

Citation: Friedman, M.; Tam, C.C.; Kim, J.H.; Escobar, S.; Gong, S.; Liu, M.; Mao, X.Y.; Do, C.; Kuang, I.; Boateng, K.; et al. Anti-Parasitic Activity of Cherry Tomato Peel Powders. Foods 2021, 10, 230. https://doi.org/10.3390/ foods10020230

Academic Editor: Marco Rosa

Received: 5 December 2020

Accepted: 21 January 2021

Published: 23 January 2021

Publisher's Note: MDPI stays neutral with regard to jurisdictional claims in published maps and institutional affiliations.

Copyright: (c) 2021 by the authors. Licensee MDPI, Basel, Switzerland. This article is an open access article distributed under the terms and conditions of the Creative Commons Attribution (CC BY) license (https:// creativecommons.org/licenses/by/ $4.0 /)$.

\begin{abstract}
Trichomoniasis in humans, caused by the protozoal parasite Trichomonas vaginalis, is the most common non-viral sexually transmitted disease, while Tritrichomonas foetus causes trichomonosis, an infection of the gastrointestinal tract and diarrhea in farm animals and domesticated cats. As part of an effort to determine the inhibitory effects of plant-based extracts and pure compounds, seven commercially available cherry tomato varieties were hand-peeled, freeze-dried, and pounded into powders. The anti-trichomonad inhibitory activities of these peel powders at $0.02 \%$ concentration determined using an in vitro cell assay varied widely from $0.0 \%$ to $66.7 \%$ against $T$. vaginalis G3 (human); from $0.9 \%$ to $66.8 \%$ for $T$. foetus C1 (feline); and from $0.0 \%$ to $81.3 \%$ for $T$. foetus D1 (bovine). The organic Solanum lycopersicum var. cerasiforme (D) peels were the most active against all three trichomonads, inhibiting 52.2\% (G3), 66.8\% (C1), and 81.3\% (D1). Additional assays showed that none of the powders inhibited the growth of foodborne pathogenic bacteria, pathogenic fungi, or non-pathogenic lactobacilli. Tomato peel and pomace powders with high content of described biologically active compounds could serve as functional food and feed additives that might help overcome adverse effects of wide-ranging diseases and complement the treatment of parasites with the anti-trichomonad drug metronidazole.
\end{abstract}

Keywords: cherry tomatoes; cherry tomato peels; cherry tomato pomace; anti-trichomonad properties; composition; food and industrial uses; animal health; human health; research needs

\section{Introduction}

Tomatoes are a low-fat food source containing nutrients that include amino acids, unsaturated fatty acids, dietary fiber, pectin, vitamins, and minerals. As noted elsewhere [1], tomatoes also produce secondary metabolites including phenolic compounds, flavonoids, pigments ( $\beta$-carotene, lycopene), phytoalexins, protease inhibitors, and glycoalkaloids. The metabolites help protect the plant against adverse effects of phytopathogenic fungi, bacteria, viruses, and insects, and have also been shown to have beneficial health effects in animals and humans.

According to the Food and Agricultural Organization of the United Nations [2], the worldwide production of tomatoes is continually increasing, approximately doubling from the year 1997 to 2017. Asia is reported to produce 54\% of the total, Europe 15.7\%, the Americas $17.6 \%$, and Africa 12\%. Both whole tomatoes and processed products, including 
tomato juice, paste and sauces, and canned dried tomatoes, are widely consumed foods. The generation of tomato-based products is accompanied by the formation of tomato pomace, consisting of tomato peels and seeds. Lu et al. [3] reviewed worldwide efforts designed to facilitate the utilization of tomato pomace as an animal feed and as a human functional food that can be added to plant- and meat-based foods.

As part of a research effort designed to discover health-promoting properties of plant extracts and their biologically active compounds to inhibit the growth of pathogenic protozoa that cause human and animal diseases, we previously reported in several publications related to the present study that the tomato glycoalkaloid tomatine [4], theaflavin-rich black tea extracts [5], potato peels, and their glycoalkaloids $\alpha$-chaconine and $\alpha$-solanine [6], and structurally different anthraquinones [7] inhibited in cell assays the growth of Trichomonas vaginalis human strain G3 that causes the sexually transmitted disease trichomoniasis mostly in women, but also in some men, Tritrichomonas foetus bovine strain D1 that causes the sexually transmitted disease in farm animals (bulls, cows, and pigs) called trichomonosis, and Tritrichomonas feline strain C1 that causes intestinal diarrhea via the oral route in domestic animals (cats and dogs), reviewed in [8]. We suggested that these naturally occurring trichomonad formulations have the potential to complement or replace the widely used synthetic drug metronidazole that is reported to exhibit a number of adverse effects and the efficacy of which is reported to be diminishing against resistant trichomonad strains [9]. The present study extends the previous anti-trichomonad results by determining the inhibitory properties of seven peel powders prepared from commercially obtained cherry (grape) tomatoes, both grown organically and non-organically, to determine if there may be differential activities associated with cultivation methods. The reported content of biologically active compounds in cherry and standard (non-cherry) tomatoes are also briefly reviewed to facilitate insights into possible relationships between the nature and levels of bioactive tomato compounds and anti-trichomonad and other reported health benefits and to stimulate needed further research.

\section{Materials and Methods}

\subsection{Plant Material, Parasite, Bacterial, and Fungal Strain Source}

Trichomonas vaginalis human strain G3 was from Patricia Johnson, University of California at Los Angeles, CA, Tritrichomonas foetus feline strain D1 was from Lynette Corbeil at the University of California at San Diego, La Jolla, CA, USA, and feline Trichomonas foetus-like organism (strain C1) was from Stanley Marks, University of California at Davis, School of Veterinary Medicine, Davis, CA, USA. The pathogenic and nonpathogenic bacteria and pathogenic fungi were obtained from the in-house United States Department of Agriculture (USDA) collection or from the American Type Culture Collection (ATCC, Manassas, VA, USA). The following seven varieties of fresh cherry tomatoes were obtained from local stores in California: Solanum lycopersicum 'Campari' non-organic, non-organic Solanum lycopersicum 'Kumato', non-organic Solanum lycopersicum var. cerasiforme (A), organic Solanum lycopersicum var. cerasiforme (B), organic Solanum lycopersicum var. cerasiforme (C), organic Solanum lycopersicum 'Roma', organic Solanum lycopersicum var. cerasiforme (D).

\subsection{Preparation of Cherry Tomato Peel Powders}

The cherry tomatoes were purchased at local stores in California. They were subjected to blanching before peeling as follows. After manual removal of the stems, they were washed with water using a brush. An X was then cut with a knife into the bottom of each tomato, which were then placed into a saucepan with boiling water for $60 \mathrm{~s}$. The tomatoes were removed using a large spoon and placed into a container with ice water. The loose peels of the cooled, wrinkled blanched tomatoes were then removed manually. All wet peels were freeze-dried (lyophilized) and the resulting dry peels were then ground to fine powders using an electric coffee grinder (Kreps, Millville, NJ, USA). The final yields of the peel powders, about $10-13 \%$, were determined from the original weights of the fruits and vegetables and those of the freeze-dried peel powders (Table 1). For example, the red 
powder from $20.5 \mathrm{~g}$ of organic red grape tomatoes weighed $2.7 \mathrm{~g}$, corresponding to a yield of $12.6 \%$.

Table 1. Weights of fresh cherry tomatoes, wet peels, and peel powders.

\begin{tabular}{|c|c|c|c|}
\hline Fresh Tomatoes (A) (g) & Wet Peels (B) (g) & Peel Powders (C) (g) & $(C / B) \times 100(D) \%$ \\
\hline $\begin{array}{l}\text { Solanum lycopersicum } \\
\text { 'Campari' non-organic, } \\
448\end{array}$ & $27.4(6.8)^{\mathrm{a}}$ & 2.7 & $9.9^{b}$ \\
\hline $\begin{array}{c}\text { Solanum lycopersicum } \\
\text { 'Kumato' non-organic, } 896\end{array}$ & $64.2(7.8)$ & 7.9 & 12.3 \\
\hline $\begin{array}{c}\text { Solanum lycopersicum var. } \\
\text { cerasiforme (A) } \\
\text { non-organic, } 896\end{array}$ & $70.6(7.9)$ & 7.3 & 10.3 \\
\hline $\begin{array}{l}\text { Organic Solanum } \\
\text { lycopersicum var. } \\
\text { cerasiforme (B), } 896\end{array}$ & $60.8(6.8)$ & 8.3 & 13.6 \\
\hline $\begin{array}{l}\text { Organic Solanum } \\
\text { lycopersicum var. } \\
\text { cerasiforme }(\mathrm{C}), 448\end{array}$ & $20.5(4.6)$ & 2.6 & 12.7 \\
\hline $\begin{array}{c}\text { Organic Solanum } \\
\text { lycopersicum 'Roma', } 896\end{array}$ & $53.8(6.0)$ & 5.5 & 10.2 \\
\hline $\begin{array}{l}\text { Organic Solanum } \\
\text { lycopersicum var. } \\
\text { cerasiforme (D), } 1344\end{array}$ & $62.7(4.7)$ & 4.1 & 4.7 \\
\hline
\end{tabular}

\subsection{Stock Solutions for Determination of Anti-Trichomonad Effects}

The cherry peel powders were dissolved in a 1:1 solution of dimethyl sulfoxide (DMSO): water to a concentration of $0.02 \%$. This solution was used as the solvent because it facilitates solubilization of test substances and has been used in our previous studies. Solutions were prepared fresh and vortexed immediately before use.

\subsection{Trichomonad Growth Inhibition Assays}

Cultures of the G3 strain of T. vaginalis and $\mathrm{C} 1$ and D1 strains of T. foetus were grown and maintained in $11 \mathrm{~mL}$ of TYM Diamond medium of $\mathrm{pH}$ 6.2. Every $24 \mathrm{~h}$, the cells from the C1, D1, and G3 strains were passed by inoculating $1000 \mu \mathrm{L}$ of cells (approximately $1 \times$ $10^{6}$ cells) into a new $15 \mathrm{~mL}$ conical tube containing $10 \mathrm{~mL}$ of TYM Diamond medium. Then, the cells were incubated for $24 \mathrm{~h}$ at $37^{\circ} \mathrm{C}$. Inhibitory screens were carried out as previously described [4-6]. These assays were incubated at $37^{\circ} \mathrm{C}$ for $24 \mathrm{~h}$ before being counted using a hemocytometer. Stock solutions were then diluted in media and tested over a range of increasing concentrations. Percentage inhibitory activities were calculated relative to the DMSO:water control at the same concentration as the test substances. There was very little if any toxicity associated with this DMSO:water solvent vehicle control.

\subsection{Bacterial and Fungal Screens}

The cherry peel powders were evaluated for their antibacterial properties in disc diffusion growth assays at a concentration of $10 \% w / v$ in DMSO:water (1:1). The negative control was 1:1 DMSO:water. Positive controls for growth inhibition for the various bacteria were discs containing the following antibiotics: levofloxacin $5 \mu \mathrm{g}$, gentamicin $10 \mu \mathrm{g}$, and gentamicin $120 \mu \mathrm{g}$. Agar plates were incubated at $37^{\circ} \mathrm{C}$ for $18-24 \mathrm{~h}$ and zones of inhibition in millimeters $(\mathrm{mm})$ were measured. None of the compounds had antibacterial activity at the concentrations tested nor did the vehicle control DMSO:water. The antifungal activity was examined in Aspergillus fumigatus AF293, a causative agent for invasive aspergillosis, 
and Candida albicans ATCC10231. DMSO:water was used as a negative vehicle control and $5 \mathrm{mM}$ octyl gallate was used for the positive control for the growth of both fungi. In both A. fumigatus and C. albicans tests, $5 \mu \mathrm{L}$ of the test powders were spotted onto the lawn of fungi (in duplicate), which were grown on Potato Dextrose Agar (PDA) or Yeast Peptone Dextrose (YPD; Bacto yeast extract 1\%, Bacto peptone 2\%, glucose 2\%) (Millipore Sigma, St. Louis, MO, USA) for A. fumigatus or C. albicans, respectively. Fungi were incubated at $35{ }^{\circ} \mathrm{C}$ and the formation of zones of inhibition in millimeters ( $\mathrm{mm}$ ) were monitored at 24 and $48 \mathrm{~h}$. None of the cherry tomatoes showed antifungal activity against the two pathogenic fungi nor did the vehicle control DMSO:water have any effect.

\subsection{Statistical Analysis}

All parasite screening trials were performed a minimum of three times on three separate days to a standard error of $\leq 0.10$. Statistical significance was determined using the Student's $t$-test to generate $p$ values in the Prism 6 software (GraphPad, San Diego, CA, USA). $p$ values $<0.05$ were considered statistically significant.

\section{Results}

\subsection{Weight Changes during Transformations of Cherry Tomatoes to Dry Peels}

Table 1 shows the observed changes in weights that have occurred during the preparation of seven cherry tomato powders from fresh cherry tomatoes. The data show that the weights of the wet peels following hand-peeling ranged from $4.6 \%$ (Organic Solanum lycopersicum var. cerasiforme C) to $7.9 \%$ or a 1.72 -fold variation from the lowest to the highest value. The last two columns show the weight changes resulting from freeze-drying the wet to dry peels. The percentage change ranged from $4.7 \%$ (Organic Solanum lycopersicum var. cerasiforme D) to $13.6 \%$ (Organic Solanum lycopersicum var. cerasiforme B) or a 2.89-fold variation from lowest to highest value. The results show no apparent major differences in weight changes between the dry peel powders derived from the three non-organic and four-organic cherry tomatoes.

\subsection{Growth Inhibition of Cherry Tomato Peel Powders against Trichomonad Parasites}

Figure 1 and Table 2 show that at concentration of $0.02 \% w / v$, six of the seven evaluated peel powders inhibited the growth of T. vaginalis G3 (human). There was very little if any toxicity associated with the vehicle control DMSO:water at the same concentration as the test powders in each experiment. In terms of percent inhibition under the test conditions, the anti-trichomonad effects ranged from 9.0\% (Solanum lycopersicum 'Kumato' non-organic) to $66.7 \%$ (Organic Solanum lycopersicum var. cerasiforme C) or a 7.4-fold variation from the lowest to highest value. The Solanum lycopersicum 'Campari' non-organic and Organic Solanum lycopersicum var. cerasiforme (D) varieties also inhibited the G3 strain at high levels of $47.2 \%$ and 52.2\%, respectively. However, the Organic Solanum lycopersicum var. cerasiforme (B) peels were inactive. A similar analysis of the data for $T$. foetus C1 (feline) in Table 2 also shows a broad range of activities from the highest value of $66.8 \%$ (Organic Solanum lycopersicum var. cerasiforme D) to the lowest value of $0.9 \%$ (Organic Solanum lycopersicum 'Roma') or a 74.2-fold variation. The inhibitory values for the six other peel powders were intermediate, ranging from 10.2\% (Organic Solanum lycopersicum var. cerasiforme C) to $38.7 \%$ (Solanum lycopersicum 'Kumato' non-organic) 


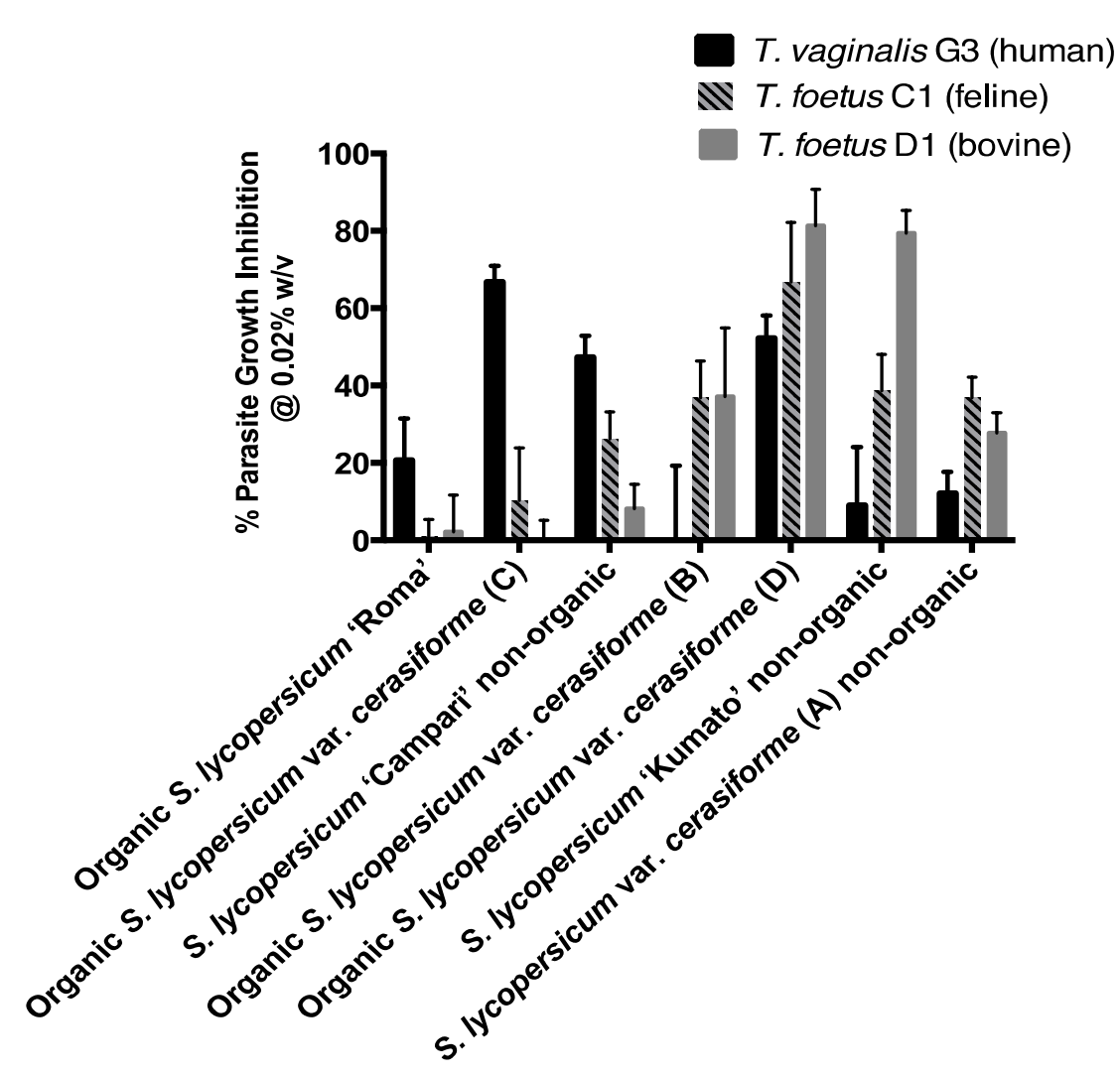

Figure 1. Cherry tomato powders and peels inhibit the growth of trichomonad parasites. The graph shows the percentage growth inhibition for T. vaginalis G3, T. foetus $\mathrm{C} 1$, and $T$. foetus D1 at the final concentration of $0.02 \% w / v$ for each powder and peel. Percentage growth inhibition was calculated relative to the DMSO:water vehicle control at the same concentration as the test substance in each experiment. There was very little if any toxicity associated with the vehicle control. Differential inhibition of parasites is observed.

Table 2. Activity of cherry tomato peel powders against three pathogenic trichomonads. The table shows the percentage growth inhibition \pm standard deviations, $n=3$, for T. vaginalis $\mathrm{G} 3, T$. foetus $\mathrm{C} 1$, and $T$. foetus $\mathrm{D} 1$ at the final concentration of $0.02 \% w / v$ for each peel powder. Percentage growth inhibition was calculated relative to the DMSO:water vehicle control at the same concentration as the test substance in each experiment. There was very little if any toxicity associated with the vehicle control. Student's $t$-test were performed for each powder to determine the statistically significance of the percent growth inhibition values for each of the three trichomonad strains to each other. $p<0.05$ were considered statistically significant. ${ }^{*} p<0.05$ for T. foetus $\mathrm{C} 1$ (feline) and T. foetus D1 (bovine) compared against T. vaginalis G3 (human); ${ }^{\mathrm{b}} p<0.05$ comparison between T. foetus D1 (bovine) and T. foetus C1 (feline).

\begin{tabular}{cccc}
\hline Cherry Tomato Names & $\begin{array}{c}\text { T. vaginalis G3 } \\
\text { (Human) }\end{array}$ & $\begin{array}{c}\text { T. foetus C1 } \\
\text { (Feline) }\end{array}$ & $\begin{array}{c}\text { T. foetus D1 } \\
\text { (Bovine) }\end{array}$ \\
\hline Solanum lycopersicum 'Campari' non-organic & $47.2 \pm 5.7$ & $26.3 \pm 6.8^{*, \mathrm{~b}}$ & $8.2 \pm 6.3^{*}$ \\
Solanum lycopersicum 'Kumato' non-organic & $9.0 \pm 15$ & $38.7 \pm 9.3^{*, \mathrm{~b}}$ & $79.4 \pm 5.9^{*}$ \\
Solanum lycopersicum var. cerasiforme (A) non-organic & $12.2 \pm 5.6$ & $36.9 \pm 5.3^{*}$ & $27.7 \pm 5.3^{*}$ \\
Organic Solanum lycopersicum var. cerasiforme (B) & $0.0 \pm 19$ & $36.9 \pm 9.5^{*}$ & $37.2 \pm 18$ \\
Organic Solanum lycopersicum var. cerasiforme (C) & $66.7 \pm 4.2$ & $10.2 \pm 14^{*}$ & $0.0 \pm 5.3^{*}$ \\
Organic Solanum lycopersicum 'Roma' & $21.0 \pm 11$ & $0.9 \pm 4.5^{*}$ & $2.2 \pm 9.6$ \\
Organic Solanum lycopersicum var. cerasiforme (D) & $52.2 \pm 5.9$ & $66.8 \pm 15$ & $81.3 \pm 9.4^{*}$ \\
\hline
\end{tabular}

The trends for T. foetus D1 (bovine) in the last column of Table 2 show that the inhibitory activities of the six peel powders ranged from 2.2\% (organic Solanum lycopersicum 'Roma') to $81.3 \%$ (organic Solanum lycopersicum var. cerasiforme D) or a 40.1 -fold variation. The Solanum lycopersicum 'Kumato' non-organic peels were also highly active, inhibiting 79.4\% 
under the test conditions. The inhibitory activities of five other peels ranged from $8.2 \%$ (Solanum lycopersicum 'Campari' non-organic) to $37.2 \%$ (organic Solanum lycopersicum var. cerasiforme B). The organic Solanum lycopersicum var. cerasiforme (C) peels were inactive. The results show large variations among the inhibitory activities of the cherry peel powders, both within each trichomonad strain as well as between the three strains with one exception. The activity of the organic Solanum lycopersicum var. cerasiforme (D) peel powder was high against all three trichomonad strains, ranging from $52.2 \%$ for the human G3, to $66.8 \%$ for the feline C1, and $81.3 \%$ for the bovine D1 strain. Using the Student's $t$-test for these percent inhibitory values for the Organic Solanum lycopersicum var. cerasiforme (D) peel powder in all three trichomonad strains, we found that there was a statistical significance between the T. vaginalis G3 (human) vs. the T. foetus D1 (bovine strain) (Table 2, $p<0.05$ ) but not for the other combinations (Table 2, $p>0.05$, T. foetus $\mathrm{C} 1$ feline vs. T. foetus D1 bovine or T. vaginalis $\mathrm{G} 3$ human vs. T. foetus $\mathrm{C} 1$ feline). This indicates that the T. foetus D1 (bovine) strain may be more susceptible to the inhibitory activities of the Solanum lycopersicum var. cerasiforme (D) peel powder in comparison to the other two trichomonad strains indicating strain susceptibility. The same statistical analysis was performed for the rest of the peel powders between all the three trichomonad strains and they are reflected in Table 2 with * and ${ }^{\mathrm{b}}$ superscripts to indicate statistical significance $p<0.05$.

\subsection{Screening of Antibacterial and Antifungal Activities of the Cherry Tomato Powders}

We also determined possible inhibitory activities of the cherry tomato peel powders against four pathogenic bacteria as well as against three nonpathogenic (commensal) lactobacilli in disc diffusion assays. The results in Table 3 show that, compared to three standard antibiotics used as positive controls, none of the peel powders was active against the four pathogenic bacteria in this assay. Table 4 shows a lack of inhibitory activity for the tomato peels against the lactobacilli and E. coli as compared to the inactivation observed with the three antibiotics. Similar negative results were observed against two fungal pathogens as compared to the activity of the positive control octyl gallate (Table 5). Additionally as shown in all the tables, the DMSO:water solvent vehicle control had no toxicity effects on the strains tested as indicated with the $0 \mathrm{~mm}$ zones of inhibition.

Table 3. The zones of inhibition in $\mathrm{mm}$ (growth inhibition) from a disc diffusion assay targeted against bacterial pathogens using DMSO:water vehicle control, antibiotic controls, and test compounds at $10 \% w / v$ in DMSO:water.

\begin{tabular}{|c|c|c|c|c|}
\hline & $\begin{array}{l}\text { Salmonella } \\
\text { enterica }\end{array}$ & $\begin{array}{c}\text { Listeria } \\
\text { monocytogenes }\end{array}$ & $\begin{array}{c}\text { Staphylococcus } \\
\text { aureus }\end{array}$ & Bacillus cereus \\
\hline DMSO:water & 0 & 0 & 0 & 0 \\
\hline Levofloxacin $5 \mu \mathrm{g}$ & 21 & 19 & 18 & 22 \\
\hline Gentamicin $10 \mu \mathrm{g}$ & 18 & 17 & 13 & 15 \\
\hline Gentamicin $120 \mu \mathrm{g}$ & 20 & 27 & 25 & 21 \\
\hline $\begin{array}{c}\text { Solanum lycopersicum 'Campari' } \\
\text { non-organic }\end{array}$ & 0 & 0 & 0 & 0 \\
\hline $\begin{array}{c}\text { Solanum lycopersicum 'Kumato' } \\
\text { non-organic }\end{array}$ & 0 & 0 & 0 & 0 \\
\hline $\begin{array}{l}\text { Solanum lycopersicum var. cerasiforme } \\
\text { (A) non-organic }\end{array}$ & 0 & 0 & 0 & 0 \\
\hline $\begin{array}{c}\text { Organic Solanum lycopersicum var. } \\
\text { cerasiforme (B) }\end{array}$ & 0 & 0 & 0 & 0 \\
\hline $\begin{array}{c}\text { Organic Solanum lycopersicum var. } \\
\text { cerasiforme (C) }\end{array}$ & 0 & 0 & 0 & 0 \\
\hline $\begin{array}{c}\text { Organic Solanum lycopersicum } \\
\text { 'Roma' }\end{array}$ & 0 & 0 & 0 & 0 \\
\hline $\begin{array}{c}\text { Organic Solanum lycopersicum var. } \\
\text { cerasiforme (D) }\end{array}$ & 0 & 0 & 0 & 0 \\
\hline
\end{tabular}


Table 4. The zones of inhibition in $\mathrm{mm}$ (growth inhibition) from a disc diffusion assay targeted against bacterial commensals using DMSO:water vehicle control, antibiotic controls, and test compounds at $10 \% w / v$ in DMSO:water.

\begin{tabular}{ccccc}
\hline & $\begin{array}{c}\text { Escherichia coli } \\
\text { K12 }\end{array}$ & $\begin{array}{c}\text { Lactobacillus } \\
\text { acidophilus }\end{array}$ & $\begin{array}{c}\text { Lactobacillus } \\
\text { rhamnosus GG }\end{array}$ & $\begin{array}{c}\text { Lactobacillus } \\
\text { reuteri }\end{array}$ \\
\hline DMSO:water & 0 & 0 & 0 & 0 \\
Levofloxacin $5 \mu \mathrm{g}$ & 20 & 0 & 16 & 7 \\
Gentamicin $10 \mu \mathrm{g}$ & 15 & 11 & 13 & 11 \\
Gentamicin $120 \mu \mathrm{g}$ & 22 & 20 & 0 & 22 \\
Solanum lycopersicum 'Campari' non-organic & 0 & 0 & 0 & 0 \\
Solanum lycopersicum 'Kumato' non-organic & 0 & 0 & 0 & 0 \\
Solanum lycopersicum var. cerasiforme(A) & 0 & 0 & 0 & 0 \\
non-organic & 0 & 0 & 0 & 0 \\
Organic Solanum lycopersicum var. cerasiforme (B) & 0 & 0 & 0 & 0 \\
Organic Solanum lycopersicum var. cerasiforme (C) & 0 & 0 & 0 & 0 \\
Organic Solanum lycopersicum 'Roma' & 0 & 0 & \\
Organic Solanum lycopersicum var. cerasiforme (D) & & & \\
\hline
\end{tabular}

Table 5. Activity of cherry tomato powders and peels against pathogenic fungi. The data indicate the calculated zone of inhibition $(\mathrm{mm})$ for each powder and peel at the designated concentration $5 \mu \mathrm{L}$ of a $10 \% w / v$ in DMSO:water with the positive control (octyl gallate) at $5 \mathrm{mM}$.

\begin{tabular}{ccc}
\hline & A. fumigatus AF293 & C. albicans ATCC10231 \\
\hline Solanum lycopersicum 'Campari' non-organic & 0.0 & 0.0 \\
Solanum lycopersicum 'Kumato' non-organic & 0.0 & 0.0 \\
Solanum lycopersicum var. cerasiforme (A) non-organic & 0.0 & 0.0 \\
Organic Solanum lycopersicum var. cerasiforme (B) & 0.0 & 0.0 \\
Organic Solanum lycopersicum var. cerasiforme (C) & 0.0 & 0.0 \\
Organic Solanum lycopersicum 'Roma' & 0.0 & 0.0 \\
Organic Solanum lycopersicum var. cerasiforme (D) & 0.0 & 0.0 \\
Octyl gallate & 6.7 & 8.0 \\
DMSO:water & 0.0 & 0.0 \\
\hline
\end{tabular}

\section{Discussion}

As mentioned earlier, tomatoes are a low-fat food source, producing both nutrients as well as biologically active compounds that include glycoalkaloids, antioxidative phenolic compounds, flavonoids, carotenes, and lycopene, all of which have been reported to have health-promoting properties (Figure 2). In our study with the seven commercially available cherry tomato varieties (three non-organic, four organic), we found differential growth inhibitory activities amongst the different varieties. The organic Solanum lycopersicum var. cerasiforme (D) powder was potent against the growth of all three trichomonad strains with the best growth inhibition targeting T. foetus D1 (Bovine). Interestingly, only two other powders showed potency $>50 \%$ growth inhibition against any of the three trichomonad strain: (a) organic Solanum lycopersicum var. cerasiforme (C) against T. vaginalis G3 (human) and (b) Solanum lycopersicum 'Kumato' non-organic against T. foetus D1 (Bovine). Our study could not determine any significant correlation relating to inhibitory activities against these three protozoan parasites and the method of cultivation (i.e., organic vs. non-organic). However, this study was complicated as these seven commercially available cherry tomato varieties were not the same 'cultivars', and genetic differences may determine the production or lack of production of important biologically active compounds that could affect our study. It is also worth noting that the drying technology used in an industrial exploitation of the results could lead to different levels of bioactivity because small-scale freeze-drying of the wet peels used in the present study is probably too expensive to be used to dry tomato peels on a large scale. In the sections below, we will discuss some important properties of tomatoes that can impact their use as food additives or functional foods. 

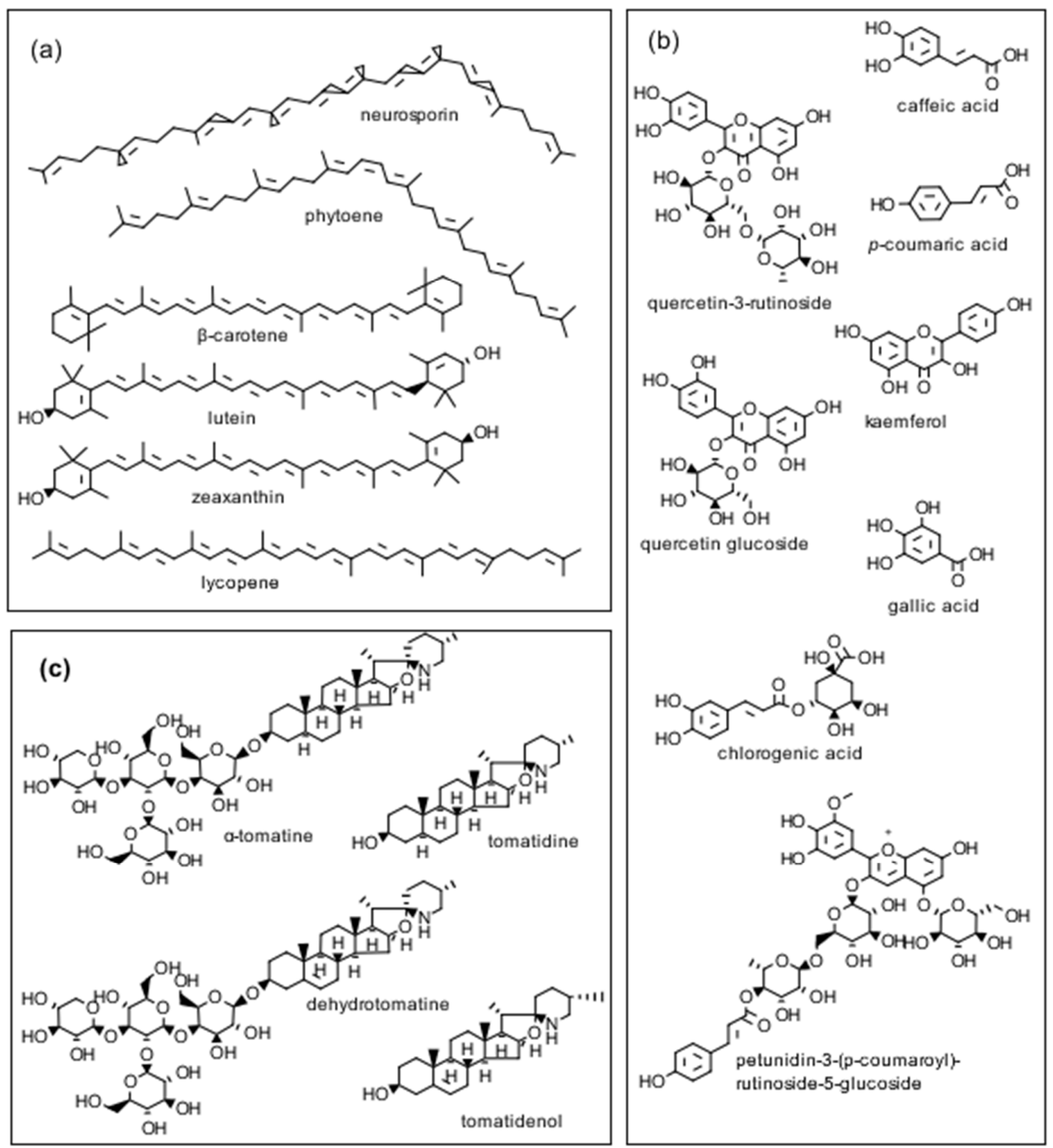

Figure 2. Structures of three classes of biologically active tomato compounds: (a) pigments, (b) phenolics, and (c) tomato glycoalkaloids discussed in the text.

\subsection{Content of Biologically Active Compounds in Cherry Tomatoes, Peels, and Pomaces}

\subsubsection{General Properties}

The properties of the biologically active compounds include antibiotic, anticarcinogenic, cardioprotective, and antilipidemic effects [10]. Both whole tomatoes and processed products that include tomato juice, paste, and sauces are widely consumed around the world. The generation of these products is accompanied by the formation of tomato pomace, considered to be a waste product, which consists of tomato peels and seeds. To facilitate the assessment of the possible relationship between the levels of biologically active compounds in tomato varieties to their potential health benefits, we present highlights from the literature on the composition of selected, predominantly cherry, tomato varieties, and genetically modified tomatoes, as well on the potential food and industrial uses of cherry tomato peels and pomace. The content of these compounds in different cherry and other tomato plants briefly outlined below might help our incomplete understanding of possible relationships between composition and bioactivity. 


\subsubsection{Analytical Aspects}

Here, we briefly summarize reported studies on the content of bioactive compounds in cherry tomatoes.

A comparison of standard and rapid extraction and chromatographic separation methods for tomato carotenoids of cherry and processing tomatoes by Dzakovich et al. [11] suggests that the rapid extraction and high-performance liquid chromatography (HPLC)diode array detector (HPLC-DAD) methods could enhance throughput for some uses compared with standard protocols. Kozukue et al. [12] reported on the analysis of the tetrasaccharide glycoalkaloids $\alpha$-tomatine and dehydrotomatine as well the corresponding aglycones tomatidine and tomatidenol lacking the carbohydrate side chain, as illustrated in Figure 2 of vegetative parts (calyxes, flowers, green and red tomato fruit, leaves, roots and stems) of greenhouse-grown cherry (mini) and two standard tomatoes using HPLC and mass spectrometry. The analytical method for tomatidine is of interest because it can be used in metabolism and pharmacology studies of reported beneficial biological properties, including anti-trichomonad [4], antiviral [13], anti-inflammatory [14], and anticancer effects [15]. Friedman et al. [16] reported on the analysis of peel powders from six commercial cherry tomato varieties for free amino acid, phenolic, flavonoid, $\beta$-carotene, lycopene, and glycoalkaloid content using HPLC/MS (mass spectrometry). In a related analytical study, we reported that the sums of the two glycoalkaloids dehydrotomatine and $\alpha$-tomatine in tomato stems, green tomato peel, and tomato leaves harvested from a tomato plant (in $\mathrm{mg} / \mathrm{g}$ dry weight, DW) are 5.14, 12.4, and 16.4, respectively [17]. These results suggest that the leaf powder might show useful biological activity.

Choi et al. [18] determined the content of water, free amino acids, amino acid metabolites, crude protein, the carotene pigments $\beta$-carotene and lycopene, and 9 characterized and 2 incompletely characterized individual phenolic (flavonoid) compounds of 12 greenhouse-grown cherry tomato varieties of various colors (green, yellow, orange, red, and black) using HPLC and LC/MS methods. The study also found that the phenolic content of the cherry tomatoes per unit weight is 3-4 times greater than reported values for large-sized tomatoes and that lycopene showed strong activity against cervical carcinoma and lung cancer cells. Bagley et al. [19] carried out a metabolomic analysis of commercial cherry tomatoes using infrared matrix-assisted laser desorption electrospray ionization (IR-M ALDESI) mass spectrometry imaging analysis. The results revealed the presence of 1626 unique compounds that included new cyanogenic glycosides, glucosinolates, and lignans. A study by Coyago-Cruz et al. [20] of the commercial quality parameters of five cherry and six non cherry tomato varieties showed that, for the cherry tomatoes, the total carotenoid content (consisting of phytoene, phytofluene, lutein, and lycopene, a $\beta$-carotene) ranged (in $\mathrm{mg} / 100 \mathrm{~g}$ DW) from 2.5 to 102.0. The corresponding range for six phenolic compounds (p-hydroxybenzoic, caffeic, chlorogenic, p-coumaric, and gallic acids and quercetin was from 150.2 to $307.7 \mathrm{mg} / 100 \mathrm{~g} \mathrm{DW}$, and for three sugars (fructose, glucose, sucrose from 308.4 to 524.1. The authors suggest that the results provide useful information on the biosynthesis and bioavailability of tomato carotenoids.

Naviglio et al. [21,22] developed an innovative low-cost high-pressure water extraction process for the trans-lycopene isomer from industrial tomato byproducts with $98 \%(w / w)$ purity and up to $14 \%(w / w)$ recovery. Silva et al. [23] used an innovative hydrophobic eutectic solvent to extract lycopene from tomato processing byproducts, suggesting that the method can also contribute to the development of greener extraction processes that can replace the use of organic solvents. Horuz et al. [24] used an electrospinning method to encapsulate carotenoids extracted from tomato peel into zein nanofibers, resulting in their improved storage and thermal stability and in an 11-fold increase in antioxidant activity.

The cited results demonstrate both wide-ranging differences as well as similarities in the content of nutritional and bioactive compounds in cherry tomatoes, and suggest that such knowledge can benefit consumers, who could select cherry tomatoes with the highest health-promoting properties. The methods described and associated results could 
also aid in the targeted development of functional foods containing cherry tomato peels with health-improving properties.

\subsubsection{Preharvest Changes of Composition during Growth of Tomato Plants}

Coyago-Cruz et al. [25] assessed the relationship between the effect of regulated deficit irrigation, cluster, developmental stages and two growth seasons on the commercial and functional quality (carotenoids and phenolic levels) of cherry tomatoes. The highest carotenoids and phenolic levels were found in the higher clusters higher up in the plant and carotenoids in ripe fruit, suggesting that irrigation of such varieties could be reduced by $80 \%$ without affecting considerably the overall fruit quality. Choi et al. [26] analyzed 11 Korean tomato varieties grown under the same greenhouse conditions and 13 processed commercial tomato products for the content of free amino acids, amino acid metabolites, protein, individual phenolics, total phenolics, and for their antioxidative activity and cancer cell-inhibiting effects. The results show a broad range of bioactive compounds across tomato varieties and products. The results of another study by Choi et al. [27] on changes in the composition of tomatoes during eleven stages of growth (S1-S11) show that the total content (in $\mathrm{mg} / 100 \mathrm{~g}$ of fresh weight, $\mathrm{FW}$ ) of the free amino acids ranged from 41 to 85 in the green tomato extracts S1-S7 and then increased to 251 (S9) in the red, followed by a decrease to 124 in S11 red; the total initial concentration of up to 12 phenolic compounds of $2000 \mu \mathrm{g} / 100 \mathrm{~g}$ of $\mathrm{FW}$ varied throughout the ripening process, with the quantity decreasing and the number of compounds increasing in the red tomato; chlorophyll $\mathrm{a}$ and $\mathrm{b}$ content of tomatoes harvested during S1 was $5.73 \mathrm{mg} / 100 \mathrm{~g}$ FW pericarp and then decreased continuously to $1.14 \mathrm{mg} / 100 \mathrm{~g}$ for S11; the concentration (in $\mathrm{mg} / 100 \mathrm{~g}$ of FW) of lycopene in the S8 red of 0.32 increased to 1.27 in S11; and tomatoes harvested during S1 contained $48.2 \mathrm{mg}$ of dehydrotomatine/100 $\mathrm{g}$ of $\mathrm{FW}$, and this value continually decreased to 1.5 in S7, with no detectable levels in S8-S11. The corresponding $\alpha$-tomatine content decreased from S1 (361) to S8 (13.8).

It seems that the harvesting stage significantly affects the composition of tomatoes, suggesting that it would benefit human health to consume both green and red tomatoes with complementary bioactive compounds. The described results may also make it possible to better relate the structures of the active compounds to their health-promoting function, individually, in combination, and in food, and allow the consumer to select food with the optimal content of nontoxic beneficial compounds.

\subsubsection{Formation of New Bioactive Tomato Compounds via Plant Genetics}

An assessment by da Silva Souza et al. [28] of the composition of two allele-introgressed tomato lines show that a purple tomato peel accumulated high amounts of the anthocyanin petunidin 3-(p-coumaroyl)-rutinoside-5-glucoside (Figure 2) and the flavonoids rutin and kaempferol, while the orange tomato accumulated high amount of $\beta$-carotene, and had a reduced lycopene level. The purple tomatoes had the highest phenolic content. Campestrini et al. [29] reported that the lutein, lycopene, and $\beta$-carotene content of a new purple tomato variety was $6,1.5$, and 2.5 times greater than that of a commercial cherry tomato variety. The authors suggest that both varieties are good sources of dietary carotenoids with health-promoting antioxidant and cancer cell inhibiting properties.

The carotenoid zeaxanthin in combination with lutein (Figure 2), are reported to delay progression of age-related macular degeneration of the retina in the human eye by filtering damaging blue light. Karniel et al. [30] used two genetic approaches to create a new tomato variety named 'Xantoato' containing $39 \mu \mathrm{g} / \mathrm{g}$ of FW (577 $\mu \mathrm{g} / \mathrm{g}$ DW) of zeaxanthin that constitutes $50 \%$ of total carotenoids in the fruit,

\subsubsection{Effect of Heat, Methyl Jasmonate, and Antimicrobial Coatings on Composition}

An investigation by D'Evoli et al. [31] on the effect of heat treatment on the carotenoid content of cherry tomatoes showed that the lycopene content in canned tomatoes was two-fold higher than in raw tomatoes $(11.60 \mathrm{mg} / 100 \mathrm{~g}$ vs. $5.12 \mathrm{mg} / 100 \mathrm{~g})$. The lutein and $\beta$ - 
carotene were, respectively, $0.15 \mathrm{mg} / 100 \mathrm{~g}$ and $0.75 \mathrm{mg} / 100 \mathrm{~g}$ in canned vs. $0.11 \mathrm{mg} / 100 \mathrm{~g}$ and $1.00 \mathrm{mg} / 100 \mathrm{~g}$ in raw tomatoes. Obadina et al. [32] investigated the quality changes of commercial cherry and plum tomatoes dried at different temperatures $(60,65$, and $70{ }^{\circ} \mathrm{C}$ ), then milled into powders and stored for 8 weeks. They found that the ascorbic acid content and lycopene content of the tomato powders were significantly different, with values that ranged from 5.10 to $7.70 \mathrm{mg} / 100 \mathrm{~g}$ and 211.53 to $246.02 \mathrm{mg} / \mathrm{kg}$, respectively. Liu et al. [33] found that postharvest treatment of cherry tomatoes with the plant hormone methyl jasmonate stored for 11 days at room temperature significantly increased the content of ascorbic acid and carotenoids, especially lycopene, as well as of volatile organic compounds in the tomato fruits, but had no effect on firmness, sugars, and titratable acidity. These observations suggest that the treatment can enhance the health benefits of the cherry tomatoes. The naturally occurring compound methyl jasmonate has also been reported to induce cell death in T. vaginalis [34,35]. Guo et al. [36] reported that carboxymethylcellulosebased films with added cinnamaldehyde and zinc oxide with antifungal activity against Aspergillus niger were significantly effective at inhibiting the weight loss and firmness of cherry tomatoes and in decreasing their total acidity after storage.

These observations are consistent with our reported antibiotic activity of cinnamaldehyde in fruit and vegetable edible films against leafy greens contaminated with pathogenic E. coli bacteria [37]. Will the edible films also protect cherry tomatoes against foodborne pathogens?

\subsection{Food and Industrial Uses of Tomato Pomace}

Nour et al. [38] reported that supplementation of wheat flour with $6 \%(w / w)$ of dry tomato waste powder resulted, after baking, in the production of bread with good sensory properties and acceptability. The authors suggest that the tomato waste containing ascorbic acid, $\beta$-carotene, lycopene, phenolic compounds, and minerals can be used as functional ingredient for the formulation of antioxidant-rich functional foods. A related study by Bajerska et al. [39] found that a high-fat diet supplemented with rye bread enriched with tomato pomace fed to rats seems to lower the atherogenic index of plasma as well as the total lipid content of the liver, suggesting that tomato pomace affects the energy balance via fecal loss of lipids. Crawford et al. [40] found that baked flatbreads prepared with quinoa flour supplemented with tomato peel powders have the potential to serve as a high nutritional, gluten-free, low-acrylamide health-promoting functional food. Raviv et al. [41] discovered that cherry tomatoes added to compost reduced the incidence of crown and root-rot disease caused by Meloidogyne javanica as well as the population size of the causal pathogen Fusarium oxysporum radicis-lycopersici. Tommonaro et al. [42] reported that industrial processing of cherry tomatoes resulted in decrease of antioxidant activity compared with that of the fresh fruit, and that a higher polyphenolic content was present in tomato juice containing peels and seeds in comparison to those without, suggesting that tomato juice prepared from cherry tomatoes might serve a useful and health-benefitting source of antioxidants in the diet. Stajčić et al. [43] determined the carotenoid content, antioxidant and growth-inhibitory activities against cancer cells of tomato waste extracts consisting of tomato peels and seeds from five different tomato genotypes. The carotenoid content was strongly correlated with the antioxidant and anti-proliferation activity. Qiu and Chin [44] found that covering low-fat pork sausages with an edible film prepared using sodium alginate and cherry tomato powder resulted in reduced lipid oxidation and microbial growth as well as in extended shelf like of the sausages. Finally, Sabio et al. [45] determined the effect of multiple variables including temperature, residence time, and biomass / water ratio on the hydrothermal carbonization of tomato peel waste into a solid hydrocarbon fuel.

The described results show that the levels of bioactive components of cherry tomatoes, tomato peels, and tomato pomaces described here vary widely and are influenced by multiple factors. Both the nature and content of biologically active tomato compounds depend on tomato variety as well as on both environmental (soil) preharvest and posthar- 
vest storage and processing of the harvested tomatoes. The cited studies described here and associated results offer insight into the multiple factors that affect the composition and biological properties of the tomato compounds shown in Figure 2, and could aid in the development of functional foods with health-improving properties, as well as in the transformation of tomato peels and pomaces to value-added industrial products.

\subsection{Nutritional and Health Benefits of Tomato Peels and Pomaces}

Vats et al. [46] suggested that tomato wastes consisting of peel and seed extracts are rich in proteins and oil that can help alleviate global malnutrition. Espinosa-Juárez et al. [47] showed that feeding high-sucrose (obese) male rats extracts of tomato pomace had a beneficial effect on lower urinary tract symptoms by enhancing prostate function. Mansoori et al. [48] found that feeding hens dried tomato pomace and alfalfa meal was effective in inducing moult, while reducing stress of severe starvation and retaining egg quality. Romano et al. [49] determined the effect of feeding sheep tomato byproducts on the composition of the resulting milk fat distribution compared to those fed a standard diet. The content of conjugated linoleic acid content (CLA) of $19.8 \%$ and of the polyunsaturated (PUFA) of $6.43 \%$ were higher than observed with the standard diet. A related study by Abbeddou et al. [50] discovered that feeding tomato pomace containing diets to lactating ewes over 7 weeks resulted in decreased saturated and polyunsaturated fatty acid and in increased content of monounsaturated including 18:1 trans fatty acids in the milk [51,52].The aggregation platelets in blood vessels play an important function in hemostasis and thrombosis associated with cardiovascular disease [53] as well as in innate immunity and in the regulation of growth of blood vessel tumors [54]. A clinical study by Palomo et al. [55] found that daily consumption of $1 \mathrm{~g}$ of aqueous extract of tomato pomace for 5 days inhibited platelet aggregation, suggesting its value to improving heart health.

\section{Conclusions}

This investigation has shown that some of the powders prepared from cherry tomato peels have anti-trichomonad, but not antibacterial or antifungal properties in vitro. Our results suggest that the organic Solanum lycopersicum var. cerasiforme (D) peel powder was effective in inhibiting the growth of all three trichomonad strains with $\geq 50 \%$. We found that there was a statistical significance between the T. vaginalis G3 (human) vs. the T. foetus D1 (bovine strain) (Table 2, $p<0.05$ ) but not for the other combinations (Table 2, $p>0.05$, T. foetus C1 feline vs. T. foetus D1 bovine or T. vaginalis G3 human vs. T. foetus C1 feline). This indicates that the T. foetus D1 (bovine) strain may be more susceptible to the inhibitory activities of the S. lycopersicum var. cerasiforme (D) peel powder in comparison to the other two trichomonad strains indicating strain susceptibility. These results in conjunction with previously published studies suggest their potential value to ameliorate the severity of trichomoniasis in infected humans and trichomoniasis in infected farm and domestic animals. The results also suggest the need for the following further studies that might help broaden the value of cherry tomato fruit, peels, and pomaces for ameliorating human and animal diseases. These include (a) clinical trials on the effectiveness of cherry tomato peels with the highest content of biologically active compounds; (b) defining the effectiveness of the peel powders against metronidazole-resistant trichomonads; (c) determining whether animal feed or human food, such as breads and flatbreads [40], and supplemented with the cherry peel powders, might act as functional feeds and foods to help protect animals and humans against trichomoniasis; $(\mathrm{d})$ developing novel methods to protect cherry tomatoes on growing plants against deterioration (spoilage) induced by phytopathogenic fungi, including Alternaria alternata [56] and aflatoxin-producing Aspergillus flavus [57-59]; and (e) determining anti-trichomonad potencies of peels from new tomato varieties that contain bioactive compounds developed via plant genetics [28,30].

We agree with the need for the following suggested further studies by a journal reviewer. "As stated by the authors, in virtue of the results here produced, one of the possible applications of peel powders would be its supplementation in foods, to ultimately 
protect animals and humans against trichomoniasis. Before in vivo trials, it is mandatory for a food chemist to prove, that salivary, gastric, and intestinal digestion, as well as metabolic processing, does not alter the anti-microbial activity of tomato peels. This experiment can be easily performed in an in vitro setting, where after each stage of simulated in vitro digestion, the processed extract is tested for anti-microbial activity. The authors should try also subjecting peel powders to metabolic processing, i.e., treating the extract with S9 microsomal fraction from rat liver. All the reagents necessary (salivary enzymes, intestinal enzymes, bile acids, ready-to-use S9 fraction) for this experiment are easy to obtain and commercially available. Adding the results of these experiments to the manuscript would augment its impact and give more insights concerning the activity of the extract. In vitro simulated digestion, for example, removes sugars from secondary metabolites. An eventual loss of anti-microbial activity would suggest the active molecules being glycosylated compounds. Paradoxically, after in vitro digestion, the peel extract could even acquire that antimicrobic or anti-fungi activity the undigested tomato peels was missing". We are challenged to respond to the mentioned research needs.

Author Contributions: M.F., K.M.L., C.C.T., and J.H.K. designed the study. S.E., S.G., M.L., X.Y.M., C.D., I.K., K.B., J.H., M.T., S.A., T.L., and R.L. performed the anti-parasite susceptibility assays. C.C.T. and J.H.K. performed the antibacterial and antifungal growth assays. M.F., C.C.T., J.H.K., L.W.C., and K.M.L. analyzed the data and wrote the paper. All authors have read and agreed to the published version of the manuscript.

Funding: This research received no external funding.

Institutional Review Board Statement: Not applicable. No animals or humans were used in this study.

Informed Consent Statement: Not applicable.

Data Availability Statement: The data generated by this study is available in this paper.

Acknowledgments: We thank Carol Levin for creating Figure 2 and for facilitating the preparation of the manuscript.

Conflicts of Interest: The authors declare no competing financial interest.

\section{References}

1. Friedman, M. Potato glycoalkaloids and metabolites: Roles in the plant and in the diet. J. Agric. Food Chem. 2006, 54, 8655-8681. [CrossRef]

2. Food and Agriculture Organization of the United Nations. FAOSTAT: Food and Agriculture Data. Available online: http: //www.faostat.fao.org (accessed on 22 April 2019).

3. Lu, Z.; Wang, J.; Gao, R.; Ye, F.; Zhao, G. Sustainable valorisation of tomato pomace: A comprehensive review. Trends Food Sci. Technol. 2019, 86, 172-187. [CrossRef]

4. Liu, J.; Kanetake, S.; Wu, Y.-H.; Tam, C.; Cheng, L.W.; Land, K.M.; Friedman, M. Anti-protozoal effects of the tomato tetrasaccharide glycoalkaloid tomatine and the aglycone tomatidine on mucosal trichomonads. J. Agric. Food Chem. 2016, 64, 8806-8810. [CrossRef] [PubMed]

5. Noritake, S.M.; Liu, J.; Kanetake, S.; Levin, C.E.; Tam, C.; Cheng, L.W.; Land, K.M.; Friedman, M. Phytochemical-rich foods inhibit the growth of pathogenic trichomonads. BMC Complement. Altern. Med. 2017, 17, 461. [CrossRef] [PubMed]

6. Friedman, M.; Huang, V.; Quiambao, Q.; Noritake, S.; Liu, J.; Kwon, O.; Chintalapati, S.; Levin, C.E.; Tam, C.; Cheng, L.W.; et al. Potato peels and their bioactive glycoalkaloids and phenolic compounds inhibit the growth of pathogenic trichomonads. J. Agric. Food Chem. 2018, 66, 7942-7947. [CrossRef] [PubMed]

7. Friedman, M.; Xu, A.; Lee, R.; Nguyen, D.N.; Phan, T.A.; Hamada, S.M.; Panchel, R.; Tam, C.C.; Kim, J.H.; Cheng, L.W.; et al. The inhibitory activity of anthraquinones against pathogenic protozoa, bacteria, and fungi and the relationship to structure. Molecules 2020, 25, 3101. [CrossRef]

8. Friedman, M.; Tam, C.C.; Cheng, L.W.; Land, K.M. Anti-trichomonad activities of different compounds from foods, marine products, and medicinal plants: A review. BMC Complement. Med. Ther. 2020, 20, 1-19. [CrossRef]

9. Bradic, M.; Warring, S.D.; Tooley, G.E.; Scheid, P.; Secor, W.E.; Land, K.M.; Huang, P.-J.; Chen, T.-W.; Lee, C.-C.; Tang, P.; et al. Genetic indicators of drug resistance in the highly repetitive genome of Trichomonas vaginalis. Genome Biol. Evol. 2017, 9, 1658-1672. [CrossRef] 
10. Friedman, M. Anticarcinogenic, cardioprotective, and other health benefits of tomato compounds lycopene, $\alpha$-tomatine, and tomatidine in pure form and in fresh and processed tomatoes. J. Agric. Food Chem. 2013, 61, 9534-9550. [CrossRef]

11. Dzakovich, M.P.; Gas-Pascual, E.; Orchard, C.J.; Sari, E.N.; Riedl, K.M.; Schwartz, S.J.; Francis, D.M.; Cooperstone, J.L. Analysis of tomato carotenoids: Comparing extraction and chromatographic methods. J. AOAC Int. 2019, 102, 1069-1079. [CrossRef]

12. Kozukue, N.; Han, J.-S.; Lee, K.-R.; Friedman, M. Dehydrotomatine and $\alpha$-tomatine content in tomato fruits and vegetative plant tissues. J. Agric. Food Chem. 2004, 52, 2079-2083. [CrossRef] [PubMed]

13. Diosa-Toro, M.; Troost, B.; van de Pol, D.; Heberle, A.M.; Urcuqui-Inchima, S.; Thedieck, K.; Smit, J.M. Tomatidine, a novel antiviral compound towards dengue virus. Antivir. Res. 2019, 161, 90-99. [CrossRef] [PubMed]

14. Chu, X.; Yu, T.; Huang, X.; Xi, Y.; Ni, B.; Zhang, R.; You, H. Tomatidine suppresses inflammation in primary articular chondrocytes and attenuates cartilage degradation in osteoarthritic rats. Aging 2020, 12, 12799-12811. [CrossRef] [PubMed]

15. Hsieh, M.H.; Yang, J.S.; Lin, R.C.; Hsieh, Y.H.; Yang, S.F.; Chang, H.R.; Lu, K.H. Tomatidine represses invasion and migration of human osteosarcoma U2OS and HOS cells by suppression of presenilin 1 and c-Raf-MEK-ERK pathway. Molecules 2020, 25, 326. [CrossRef]

16. Friedman, M.; Sakakibara, H.; Mizuno, M.; Kim, D.-H.; Kozukue, N. Free amino acid, phenolic, flavonoid, $\beta$-carotene, lycopene, dehydrotomatine, and $\alpha$-tomatine content of peel powders prepared from commercial cherry tomatoes. Curr. Top. Phytochem. 2020, 16. In press.

17. Friedman, M.; Kozukue, N.; Mizuno, M.; Sakakibara, H.; Choi, S.-H.; Fujitake, M.; Land, K.M. The analysis of the content of biologically active phenolic compounds, flavonoids, and glycoalkaloids in harvested red, yellow, and green tomatoes, tomato leaves, and tomato stems. Curr. Top. Phytochem. 2019, 15, 43-53.

18. Choi, S.H.; Kim, D.-S.; Kozukue, N.; Kim, H.-J.; Nishitani, Y.; Mizuno, M.; Levin, C.E.; Friedman, M. Protein, free amino acid, phenolic, $\beta$-carotene, and lycopene content, and antioxidative and cancer cell inhibitory effects of 12 greenhouse-grown commercial cherry tomato varieties. J. Food Compos. Anal. 2014, 34, 115-127. [CrossRef]

19. Bagley, M.C.; Pace, C.L.; Ekelöf, M.; Muddiman, D.C. Infrared matrix-assisted laser desorption electrospray ionization (IRMALDESI) mass spectrometry imaging analysis of endogenous metabolites in cherry tomatoes. Analyst 2020, 145, 5516-5523. [CrossRef]

20. Coyago-Cruz, E.; Corell, M.; Moriana, A.; Mapelli-Brahm, P.; Hernanz, D.; Stinco, C.M.; Beltrán-Sinchiguano, E.; MeléndezMartínez, A.J. Study of commercial quality parameters, sugars, phenolics, carotenoids and plastids in different tomato varieties. Food Chem. 2019, 277, 480-489. [CrossRef]

21. Naviglio, D.; Pizzolongo, F.; Ferrara, L.; Aragòn, A.; Santini, A. Extraction of pure lycopene from industrial tomato by-products in water using a new high-pressure process. J. Sci. Food Agric. 2008, 88, 2414-2420. [CrossRef]

22. Naviglio, D.; Caruso, T.; Iannece, P.; Aragon, A.; Santini, A. Characterization of high purity lycopene from tomato wastes using a new pressurized extraction approach. J. Agric. Food Chem. 2008, 56, 6227-6231. [CrossRef] [PubMed]

23. Silva, Y.P.A.; Ferreira, T.; Jiao, G.; Brooks, M.S. Sustainable approach for lycopene extraction from tomato processing by-product using hydrophobic eutectic solvents. J. Food Sci. Technol. 2019, 56, 1649-1654. [CrossRef] [PubMed]

24. Horuz, T.; Belibağlı, K.B. Nanoencapsulation of carotenoids extracted from tomato peels into zein fibers by electrospinning. J. Sci. Food Agric. 2019, 99, 759-766. [CrossRef] [PubMed]

25. Coyago-Cruz, E.; Corell, M.; Moriana, A.; Hernanz, D.; Benítez-González, A.M.; Stinco, C.M.; Meléndez-Martínez, A.J. Antioxidants (carotenoids and phenolics) profile of cherry tomatoes as influenced by deficit irrigation, ripening and cluster. Food Chem. 2018, 240, 870-884. [CrossRef]

26. Choi, S.-H.; Kim, H.-R.; Kim, H.-J.; Lee, I.-S.; Kozukue, N.; Levin, C.E.; Friedman, M. Free amino acid and phenolic contents and antioxidative and cancer cell-inhibiting activities of extracts of 11 greenhouse-grown tomato varieties and 13 tomato-based foods J. Agric. Food Chem. 2011, 59, 12801-12814. [CrossRef]

27. Choi, S.-H.; Lee, S.-H.; Kim, H.-J.; Lee, I.-S.; Kozukue, N.; Levin, C.E.; Friedman, M. Changes in free amino acid, phenolic, chlorophyll, carotenoid, and glycoalkaloid contents in tomatoes during 11 stages of growth and inhibition of cervical and lung human cancer cells by green tomato extracts. J. Agric. Food Chem. 2010, 58, 7547-7556. [CrossRef]

28. da Silva Souza, M.A.; Peres, L.E.; Freschi, J.R.; Purgatto, E.; Lajolo, F.M.; Hassimotto, N.M. Changes in flavonoid and carotenoid profiles alter volatile organic compounds in purple and orange cherry tomatoes obtained by allele introgression. J. Sci. Food Agric. 2020, 100, 1662-1670. [CrossRef]

29. Campestrini, L.H.; Melo, P.S.; Peres, L.E.P.; Calhelha, R.C.; Ferreira, I.; Alencar, S.M. A new variety of purple tomato as a rich source of bioactive carotenoids and its potential health benefits. Heliyon 2019, 5, e02831. [CrossRef]

30. Karniel, U.; Koch, A.; Zamir, D.; Hirschberg, J. Development of zeaxanthin-rich tomato fruit through genetic manipulations of carotenoid biosynthesis. Plant. Biotechnol. J. 2020, 18, 2292-2303. [CrossRef]

31. D'Evoli, L.; Lombardi-Boccia, G.; Lucarini, M. Influence of heat treatments on carotenoid content of cherry tomatoes. Foods 2013, 2, 352-363. [CrossRef]

32. Obadina, A.; Ibrahim, J.; Adekoya, I. Influence of drying temperature and storage period on the quality of cherry and plum tomato powder. Food Sci. Nutr. 2018, 6, 1146-1153. [CrossRef] [PubMed]

33. Liu, H.; Meng, F.; Miao, H.; Chen, S.; Yin, T.; Hu, S.; Shao, Z.; Liu, Y.; Gao, L.; Zhu, C.; et al. Effects of postharvest methyl jasmonate treatment on main health-promoting components and volatile organic compounds in cherry tomato fruits. Food Chem. 2018, 263, 194-200. [CrossRef] [PubMed] 
34. Vilela, R.; Menna-Barreto, R.F.S.; Benchimol, M. Methyl jasmonate induces cell death and loss of hydrogenosomal membrane potential in Trichomonas vaginalis. Parasitol. Int. 2010, 59, 387-393. [CrossRef] [PubMed]

35. Ofer, K.; Gold, D.; Flescher, E. Methyl jasmonate induces cell cycle block and cell death in the amitochondriate parasite Trichomonas vaginalis. Int. J. Parasitol. 2008, 38, 959-968. [CrossRef] [PubMed]

36. Guo, X.; Chen, B.; Wu, X.; Li, J.; Sun, Q. Utilization of cinnamaldehyde and zinc oxide nanoparticles in a carboxymethylcellulosebased composite coating to improve the postharvest quality of cherry tomatoes. Int. J. Biol. Macromol. 2020, 160, 175-182. [CrossRef] [PubMed]

37. Zhu, L.; Olsen, C.; McHugh, T.; Friedman, M.; Levin, C.E.; Jaroni, D.; Ravishankar, S. Edible films containing carvacrol and cinnamaldehyde inactivate Escherichia coli O157:H7 on organic leafy greens in sealed plastic bags. J. Food Saf. 2020, 40, e12758 [CrossRef]

38. Nour, V.; Ionica, M.E.; Trandafir, I. Bread enriched in lycopene and other bioactive compounds by addition of dry tomato waste. J. Food Sci. Technol. 2015, 52, 8260-8267. [CrossRef]

39. Bajerska, J.; Chmurzynska, A.; Mildner-Szkudlarz, S.; Drzymała-Czyż, S. Effect of rye bread enriched with tomato pomace on fat absorption and lipid metabolism in rats fed a high-fat diet. J. Sci. Food Agric. 2015, 95, 1918-1924. [CrossRef]

40. Crawford, L.M.; Kahlon, T.S.; Wang, S.C.; Friedman, M. Acrylamide content of experimental flatbreads prepared from potato, quinoa, and wheat flours with added fruit and vegetable peels and mushroom powders. Foods 2019, 8, 228. [CrossRef]

41. Raviv, M.; Oka, Y.; Katan, J.; Hadar, Y.; Yogev, A.; Medina, S.; Krasnovsky, A.; Ziadna, H. High-nitrogen compost as a medium for organic container-grown crops. Bioresour. Technol. 2005, 96, 419-427. [CrossRef]

42. Tommonaro, G.; De Prisco, R.; Pergamo, R.; Iodice, C.; Abbamondi, G.R.; Spagnuolo, A.; Nicolaus, B. Effects of industrial processes on antioxidant power and polyphenols profile in cherry tomato cultivar. J. Med. Food 2015, 18, 1173-1178. [CrossRef] [PubMed]

43. Stajčić, S.; Ćetković, G.; Čanadanović-Brunet, J.; Djilas, S.; Mandić, A.; Četojević-Simin, D. Tomato waste: Carotenoids content, antioxidant and cell growth activities. Food Chem. 2015, 172, 225-232. [CrossRef] [PubMed]

44. Qiu, Z.Z.; Chin, K.B. Physicochemical properties and shelf-life of low-fat pork sausages wrapped with active film manufactured by sodium alginate and cherry tomato powder. Asian Australas. J. Anim. Sci. 2020, 33, 1470-1476. [CrossRef] [PubMed]

45. Sabio, E.; Álvarez-Murillo, A.; Román, S.; Ledesma, B. Conversion of tomato-peel waste into solid fuel by hydrothermal carbonization: Influence of the processing variables. Waste Manag. 2016, 47, 122-132. [CrossRef] [PubMed]

46. Vats, S.; Bansal, R.; Rana, N.; Kumawat, S.; Bhatt, V.; Jadhav, P.; Kale, V.; Sathe, A.; Sonah, H.; Jugdaohsingh, R.; et al. Unexplored nutritive potential of tomato to combat global malnutrition. Crit. Rev. Food Sci. Nutr. 2020, 10, 1-32. [CrossRef] [PubMed]

47. Espinosa-Juarez, J.V.; Colado-Velazquez, J.I.; Mailloux-Salinas, P.; Medina-Contreras, J.; Correa-Lopez, P.V.; Gomez-Viquez, N.L.; Meza-Cuenca, F.; Huang, F.; Bravo, G. Beneficial effects of lipidic extracts of saladette tomato pomace and Serenoa repens on prostate and bladder health in obese male Wistar rats. J. Sci. Food Agric. 2017, 97, 4451-4458. [CrossRef] [PubMed]

48. Mansoori, B.; Modirsanei, M.; Farkhoy, M.; Kiaei, M.M.; Honarzad, J. The influence of different single dietary sources on moult induction in laying hens. J. Sci. Food Agric. 2007, 87, 2555-2559. [CrossRef] [PubMed]

49. Romano, R.; Masucci, F.; Giordano, A.; Musso, S.S.; Naviglio, D.; Santini, A. Effect of tomato by-products in the diet of Comisana sheep on composition and conjugated linoleic acid content of milk fat. Int. Dairy J. 2010, 20, 858-862. [CrossRef]

50. Abbeddou, S.; Rischkowsky, B.; Hilali Mel, D.; Haylani, M.; Hess, H.D.; Kreuzer, M. Supplementing diets of Awassi ewes with olive cake and tomato pomace: On-farm recovery of effects on yield, composition and fatty acid profile of the milk. Trop. Anim. Health Prod. 2015, 47, 145-152. [CrossRef]

51. Fuke, G.; Nornberg, J.L. Systematic evaluation on the effectiveness of conjugated linoleic acid in human health. Crit. Rev. Food Sci. Nutr. 2017, 57, 1-7. [CrossRef]

52. Bazinet, R.P.; Laye, S. Polyunsaturated fatty acids and their metabolites in brain function and disease. Nat. Rev. Neurosci. 2014, 15, 771-785. [CrossRef] [PubMed]

53. McEwen, B.J. The influence of diet and nutrients on platelet function. Semin. Thromb. Hemost. 2014, 40, 214-226. [CrossRef] [PubMed]

54. Holinstat, M. Normal platelet function. Cancer Metastasis Rev. 2017, 36, 195-198. [CrossRef] [PubMed]

55. Palomo, I.; Concha-Meyer, A.; Lutz, M.; Said, M.; Saez, B.; Vasquez, A.; Fuentes, E. Chemical Characterization and Antiplatelet Potential of Bioactive Extract from Tomato Pomace (Byproduct of Tomato Paste). Nutrients 2019, 11, 456. [CrossRef] [PubMed]

56. Akroum, S.; Rouibah, M. Protection by some plant methanol extracts of cherry tomatoes (Solanum lycopersicum var. cerasiforme) from fungic infection by Alternaria alternata. Biol. Aujourd'hui 2020, 214, 55-61. [CrossRef]

57. Kazemi, M. Effect of Carum copticum essential oil on growth and aflatoxin formation by Aspergillus strains. Nat. Prod. Res. 2015, 29, 1065-1068. [CrossRef] [PubMed]

58. Tian, J.; Zeng, X.; Zeng, H.; Feng, Z.; Miao, X.; Peng, X. Investigations on the antifungal effect of nerol against Aspergillus flavus causing food spoilage. Sci. World J. 2013, 2013, 230795. [CrossRef]

59. Kim, J.H.; Cheng, L.W.; Chan, K.L.; Tam, C.C.; Mahoney, N.; Friedman, M.; Shilman, M.M.; Land, K.M. Antifungal Drug Repurposing. Antibiotics 2020, 9, 812. [CrossRef] 